ISSN 2076-0752

www.mdpi.com/journal/arts

Book Review

\title{
Walking and Mapping: Artists as Cartographers. By Karen O’Rourke. Cambridge, MA. MIT Press, 2013.
}

\author{
Joel Weishaus
}

Artist-in-Residence, Pacifica Graduate Institute, Carpinteria, CA., USA; E-Mail: weishaus@pdx.edu; Tel. +1-503-274-8572

Received: 5 June 2014 / Accepted: 13 June 2014 / Published: 16 June 2014

\begin{abstract}
While there is a long well-documented tradition of poets walking and writing about the landscape, for at least the past fifty years visual artists have been laying out walks as various kinds of artwork. More recently, with the technology of mapping morphing into electronic devices, artists have begun using these tools to develop entirely new genres.
\end{abstract}

Keywords: Walking and mapping as an art; surveillance; psychogeography

One theory as to why proto-humans left the relative safety of trees, to which some of our primate relatives still cling, is that too many of their children were falling from them to their death. Another is that they realized that a larger variety of foodstuffs was available at ground level. Whatever the reason, what's of interest here is not why they came down, but why they eventually began walking on two legs instead of four. Perhaps it was because, while running on two limbs may have been slower than on all four, it allowed for viewing a greater distance across the African savannah, giving them an edge over predators and prey.

Because the evolutionary process is an entanglement of practicalities and mutations usually occurring over a very long period of time, and because cultural transitions can be only be theorized using information gleaned from artifacts, the path to modern humans remains the lively subject discussion by archaeologists, evolutionary biologists, and other scientists. However, thanks to new technologies, we now know that humans began working out a symbolic language as early as 150,000 years ago. 
Figure 1. Walking and Mapping: Artists as Cartographers. Book Cover.

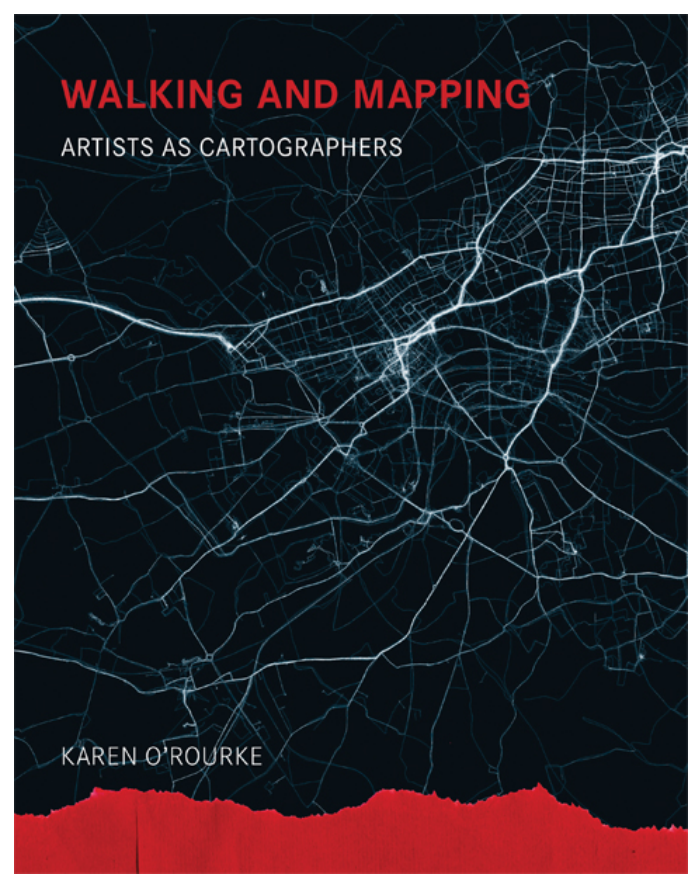

While our sense of mapping seems to be a built-in attribute of the primate brain, it was the freeing of our hands from walking that allowed us to objectify our neurological map, by using sticks to scratch into the ground a common language of signs that didn't need further articulation. Over the course of time our maps not only became more complex, but also artfully ornate. Now, in an age of GPS locational devices, a globally-connected Internet, and satellites with high-resolution cameras, the definition of what constitutes a map, along with the process of mapping, is changing again.

\section{"Mapping denotes a process that takes place every time a map of any kind is created - a drawing scribbled on the back of an envelope, a sequence of places or events etched in one's memory, an itinerary generated on the fly by an online route-finding service, or a projection prepared by a team of professional cartographers."(p.viii)}

There is a long well-documented tradition of poets walking and writing about the landscape. For at least the past fifty years visual artists have been laying out walks as various kinds of artwork. More recently, with the technology of mapping morphing into electronic devices, artists have begun using these tools to develop entirely new genres. Thus, On October 17, 2004, in her home city of Paris, artist and writer Karen O'Rourke participated in a "psychogeographical walk" with about twenty other persons. It was orchestrated by Dutch artist/philosopher, Wilfried Hou Je Bek, who, briefly, defines psychogeography as "the fact that you have an opinion about a space the moment you step into it. This has as much to do with the space as with our hardwired instincts to determine if it is safe."(p.6)

Equipped with just a pencil and paper, the pedestrians were given an algorithm and instructed to follow it for an hour. O'Rourke's card read: "first right; first left; third right; repeat." As she walked, she wondered, “What exactly is a 'first left?' Does this unmarked lane qualify, or should I wait for something more important?" They were not to look for names; rather, qualities that stuck in their mind 
were an inspiration for them to offer a name. Everyone, especially visitors to those Parisian streets, found this difficult, because, like a neural map, our relationship to an environment is built over time and repetition. But Hou Je Beck pointed out that 'naming' itself serves to create an emotional relationship.

Finally, with their annotated maps in hand, the group returned to Hou Je Bek, who translated them into a language he invented, called L-Expression, and subsequently gave them to Philadelphia-based artist Orkan Telhan. The finished project was projected on a plasma screen at the The Naked City exhibition, held in Orleans, France, in 2004. One can see here how contemporary art practices are becoming a network of international collaborations.

O'Rourke discusses the many ways artists around the world have been theorizing their work in various attitudes of walking. For example, Ivan Chicheglov, who in 1953 portrayed an "ideal city of the future in which drifting is the main activity of its inhabitants. Landscapes that change from one hour to the next will result in complete disorientation. All the other arts will be superseded by architecture."(p.9). The concept of drifting was later pursued by Guy Debord, in his "Theory of the Drift," in which a person is given an appointment at which "he (or she) may meet no one, or he may even by chance meet the person who has arranged the 'possible rendezvous.' In any case, particularly if the time and place have been well chosen, his use of time will take an unexpected turn."(p.10)

There is "algorithmic walking," which began with the Situationists, for whom walking "was not something you actually did." (p.11) There's also, "playful pedestrianism," in which the performance artist Shiraga Kazuo, "dipped his feet in paint and walked over an expanse of canvas he had placed on the floor," and Atsuko Tanaka, "walked through an exhibition openings wearing an Electric Dress."(p.12) Or Bruce Nauman's ritual, in which he walked while "making faces or pacing-to inventory the different ways he could walk around his studio, varying parameters like gait, rhythm, speed, angle, balance."(p.31) Echoing Marcel Duchamp (see below), Nauman proclaimed that, "if I was an artist and I was in the studio, then whatever I was doing in the studio must be art." (p.47)

In the third section of the book, entitled, "A Map with No Directions," O'Rourke outlines several "Walking Protocols." "(I)n contemporary art," she writes, "a protocol is a set of rules that an artist establishes to realize an artwork. It is a statement of intention and informs the viewer's understanding of the results." (p.49) Perhaps the most famous artist engaged in this process is Richard Long, who "sees walking as a means to explore relationships between time, distance, geography and measurement."

Long is one of the group of artists who in the 1960s began appropriating land as their canvas, in some most cases disrupting its ecology in the wake of making their art. Although there was a brief physical commitment, usually no mutual long-time relationship with the land was established. In contrast to the many site-based poets, the visual artists didn't settle into the place, but documented the results of their work with photographs and notes, with which they returned to their urban homes and art dealers.

From here, Walking and Mapping deepens into a discussion of Australian Aboriginal ways of orientation. Although there is now a thriving market of Aboriginal map-based art, for these people mapping, passed along as so-called "songlines," "has been a matter of life or death." For example, 
"the Luritja of central Australia, who were driven from the territory by four years of drought and yet survived thanks to the precise topographic memory of their elders. From experience gained years before and the instructions of their grandfathers, they were able to find the chain of tiny water holes that led them out of the desert to safety."(p.118)

"For the Australian Aborigines," O'Rourke continues, "territory is not a piece of land enclosed within borders but 'an interlocking network of 'lines' or 'ways through."' In north Queensland, Guuga Yimithirr is a "geographical Language" that orients its speakers only in cardinal directions. "In addition, GY routinely uses apparent body-part words such as baru 'chin' or ngada 'back of the knee...

Thus, one hears such expressions as baru nguundu (lit., chin towards here, i.e. 'facing towards here' or ngada wugurr (lit, follow the back of [his] knee, i.e., 'walk behind him his back to you)"' [1].

The danger here is that, like with the indigenous people of North America and elsewhere, Australian Aboriginal rituals and spiritual orientations are usually misrepresented by well-meaning, but uninitiated, individuals. It would have been better if the author had taken the opportunity to inscribe this caution. Although aboriginal peoples can teach Western Culture about the somatic relationship to the earth it has lost in its mad dash to industrialize, art projects such as outlined in this book, circumscribed as they are within a Western art historical format, may actually move us in the wrong direction from an appropriate way to recover aboriginal knowledge within a modern society. In other words, there is measure of naiveté here that re-presents the problem that first arose when Modernist artists such as Picasso began incorporating African motifs into their work as if they were their original thought.

Returning to the recent past: In 2000, Chinese performance artists Yuan Chai and Jian Jun Xi entered London's Tate Modern Museum, walked up to Marcel Duchamp's infamous "Fountain," which was sealed within a plastic case, and pantomimed peeing into the iconic urinal. They claimed they were adding to what Duchamp had declared was, because he was an artist, an Objet d'art.

Although before Duchamp's "readymades," the Dadaists, Futurists, and others were already dismantling definition of what art may be, most of the Art World still thought it knew what art was. Basically, you were a painter or a sculptor. The essence of art, its innate beauty and profundity, was glimpsed through these two keyholes.

The expansion of art's definition during the $20^{\text {th }}$ Century leads us to the book's last chapter, "Mapping "Ways Through;"' in particular, to one of its subtitles, "Lines for Which Millions Have Died." In a world in which, because of war, extreme poverty, political, religious and sexual repression, there are large migrations of people between countries, some of the absurdities of immigration are raised in a telling project by Francis Alÿs. In 1997, the Belgian artist crossed the border between the United States and Mexico by traveling from Tijuana south to Chile, flying to Australia, then to Hong Kong, Alaska, Vancouver...finally arriving in San Diego, CA., about 15 miles from where he began, in Tijuana. Documenting his five-week journey with postcards, the artist circumvented the US Border Patrol by exaggerating the irony of national borders in general, especially those that make no ecological sense.

O'Rourke also recognizes "the shift from the disciplinary regime (that Michel Foucault wrote about in Discipline and Punish) to the controlled society (defined by Gilles Deleuze)," (p.208) to which, as new surveillance technologies come on-line, societies who value private space are succumbing. For 
example, in 2001, after the attack on its World Trade Center, 1500 closed-circuit surveillance cameras were added to existing units on New York City's streets and subways. "An effective way to communicate concerns about surveillance is to chart the location of closed-circuit TV cameras on an online map and make the information public," O'Rourke writes. These "paths of least surveillance" allow people to "move through public space without being filmed by unregulated surveillance cameras.”(p.212) However, especially after recent revelations of the National Security Agency's massive intrusions into the private communications, broader philosophical and legal strategies, along with investigative reporting and whistleblowing by those working inside such agencies, are called for. Whether artists can play a useful role here is to be seen.

This book is recommended for artists who wish to explore other means than those that, even in midst of a technological revolution, remain the genres most discussed by art critics. In effect, it is a valuable guidebook for what the "Action Painters" of the 1950s may have done if they had abandoned their lofts and creatively walked the actual Terra Incognita. As Richard Long said:

"If you undertake a walk, you are echoing the whole history of mankind, from the early migrations out of Africa on foot that took people all over the world. Despite the many traditions of walking - the landscape walker, the walking poet, the pilgrim — it is always possible to walk in different ways." (p.247)

\section{Conflicts of Interest}

The author declares no conflict of interest.

\section{References and Notes}

1. Haviland, John B. "Guugu Yimithirr Cardinal Directions. Ethos 26 (1), March 1998, pp. 25-47 (Punctuation slightly altered.)

(C) 2014 by the authors; licensee MDPI, Basel, Switzerland. This article is an open access article distributed under the terms and conditions of the Creative Commons Attribution license (http://creativecommons.org/licenses/by/3.0/). 